\title{
Synthesis and Biological Activity of Highly Cationic
}

\section{Dendrimer Antibiotics}

Harrison W. VanKoten ${ }^{1}$, Wendy M. Dlakic ${ }^{1}$, Robert Engel ${ }^{2}$, Mary J. Cloninger ${ }^{1 *}$

${ }^{1}$ Department of Chemistry and Biochemistry, 103 Chemistry and Biochemistry Building,

Montana State University, Bozeman, MT 59717, USA.

${ }^{2}$ Department of Chemistry and Biochemistry, 65-30 Kissena Blvd., Queens College,

CUNY, Queens, NY 11367, USA

Email: Mary Cloninger - mcloninger@chemistry.montana.edu

${ }^{*}$ Corresponding author

\section{Supporting Information Table of Contents}

General protocol for determining zeta potential General protocol for determining CMC

S2

Figure S1. Electrophoretic mobility plot

S2

Figure S2. CMC plot

S2

Figure S3. ${ }^{1} \mathrm{H}$ and ${ }^{13} \mathrm{C}$ NMR spectrum of 1

S3

Figure S4. MALDI spectra of 1

S4

Figure S5. Hemolysis Data for 1 and 2

S5

Figure S6. Structure of G(4) PAMAM dendrimer

S5

Table S1. MIC values for 1 and 2

S6

Sample calculation for active group MIC

S7

Figure S7. Biofilm Disruption Studies

S7

S8 


\section{General procedure for determining charge of $\mathrm{C}_{16}-\mathrm{DABCO}$ dendrimers.}

A $0.01 \mathrm{mM}$ solution of $\mathrm{C}_{16}$-DABCO dendrimers was dissolved in filtered (0.022 $\mu \mathrm{m}$ filter) Millipore water. $100 \mu \mathrm{L}$ of the solution was placed into Wyatt Technologies' Mobius Dip Cell to perform the electrophoretic mobility experiment. The triangle extending above the $y$-axis indicates $\mathrm{C}_{16}$-DABCO dendrimers are positively charged. It is noteworthy, that the positive charge appears after the addition of $\mathrm{C}_{16}$-DABCO. Generally speaking, unfunctionalized glycodendrimers are neutral in charge.

\section{General Procedure for Determining Critical Micelle Concentration}

Experiments were performed to ensure that $\mathrm{C}_{16}$-DABCO was below the critical micelle concentration (CMC). Several concentrations of $\mathrm{C}_{16}$-DABCO were dissolved in water (Millipore) and filtered through a $0.22 \mu \mathrm{m}$ syringe filter to ensure no dust or other contaminants were present in the sample. Samples were analyzed on a 90 plus Particle Size Analyzer made by Brookhaven Instruments Corporation. The graph in Figure S4 represents several overlapping data acquisitions. The two regression lines represent the intensity changes as a function of concentration of $\mathrm{C}_{16}$-DABCO. One line shows data prior to micelle formation, and the other line is after formation of micellular aggregates. The intersection point shows the concentration at which micelles begin to form. From this experimental data, the critical micelle concentration was determined to be 0.685 $\mathrm{mM}$. This concentration is well above the concentrations reported throughout this publication for $\mathrm{C}_{16}$-DABCO use in assays.

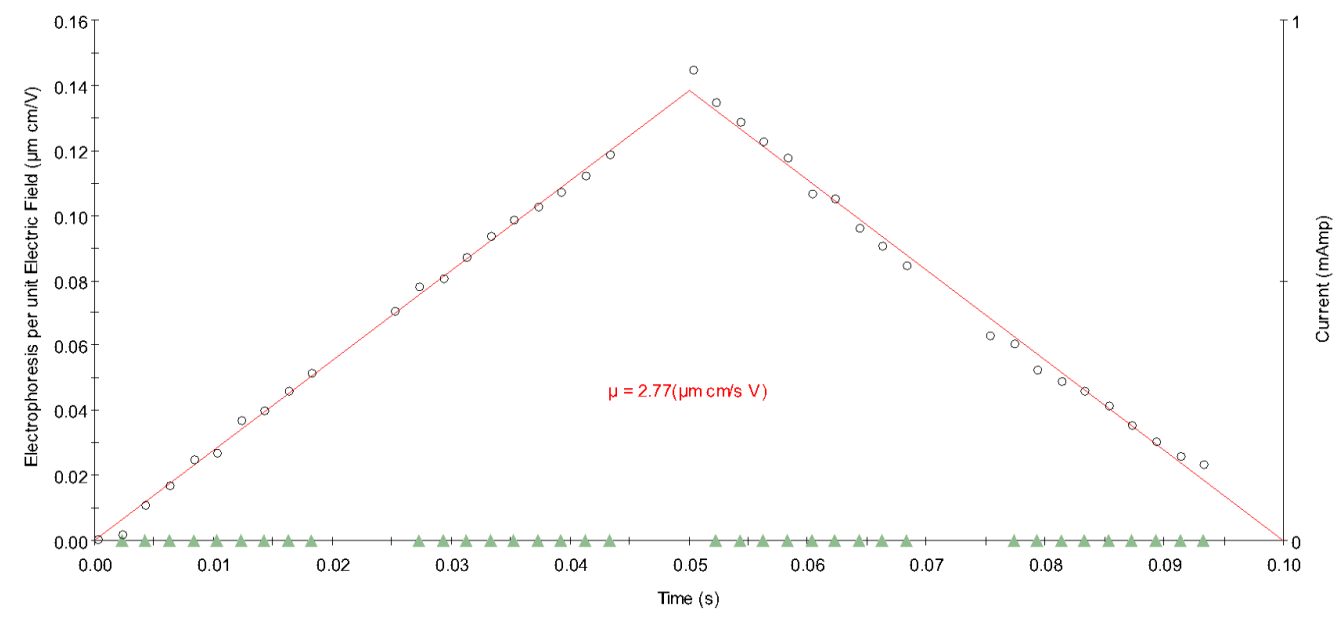

Figure S1. Electrophoretic mobility plot for $\mathrm{C}_{16}$-DABCO dendrimers. 
S3

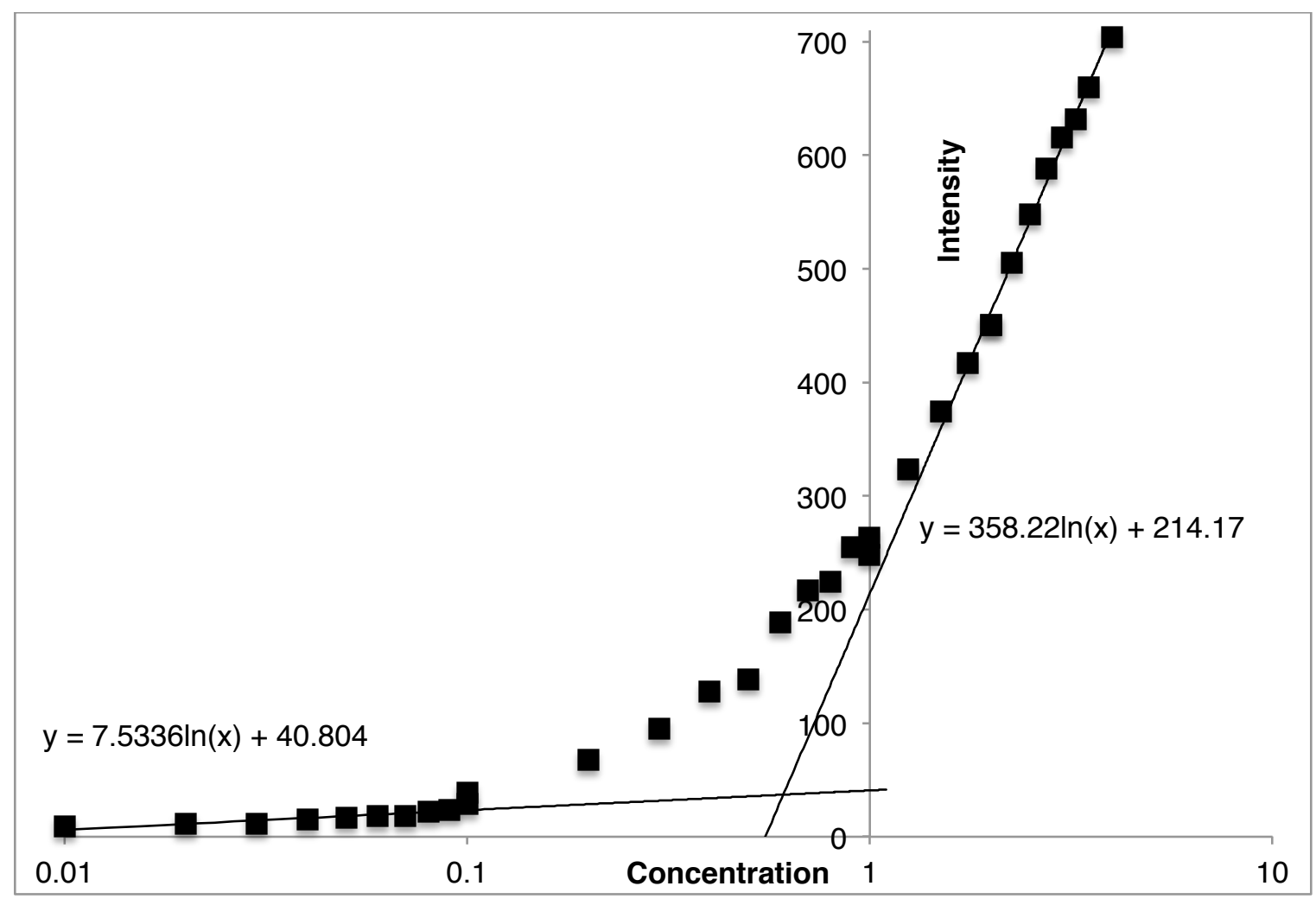

Figure S2. CMC determination for 1. 


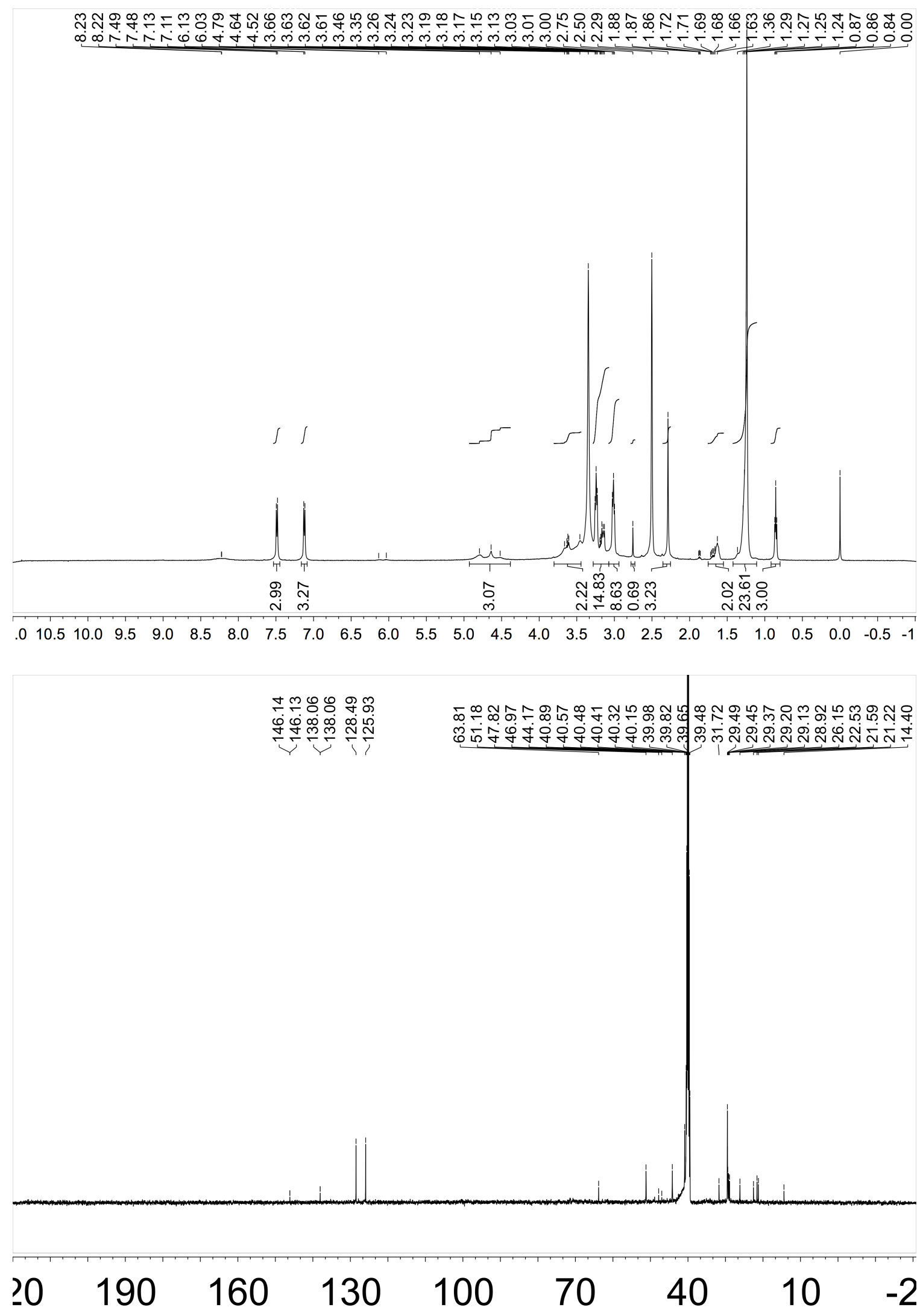

Figure S3. ${ }^{1} \mathrm{H}$ NMR spectrum (top) and ${ }^{13} \mathrm{C}$ NMR spectrum (bottom) of 1. 

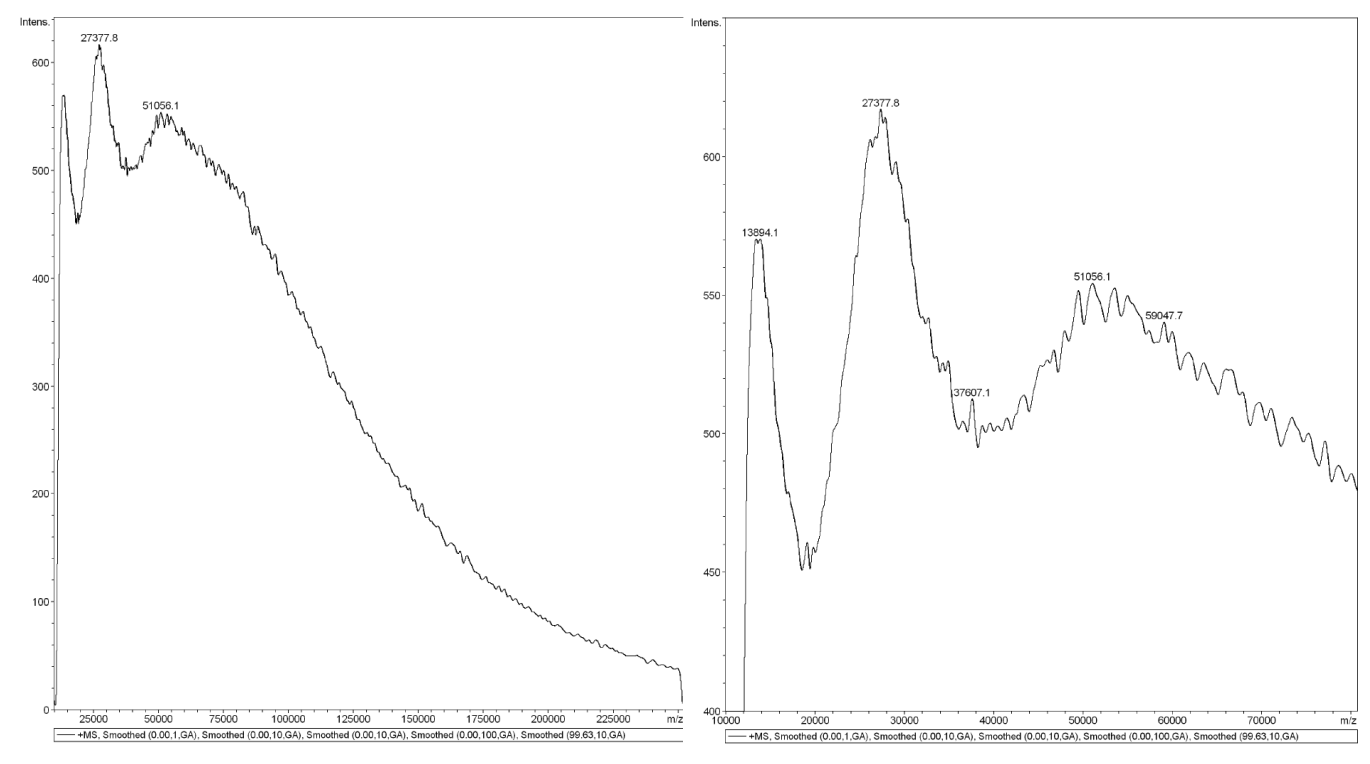

Figure S4. MALDI-TOF MS of 1. Full spectrum on left and zoom view on right.

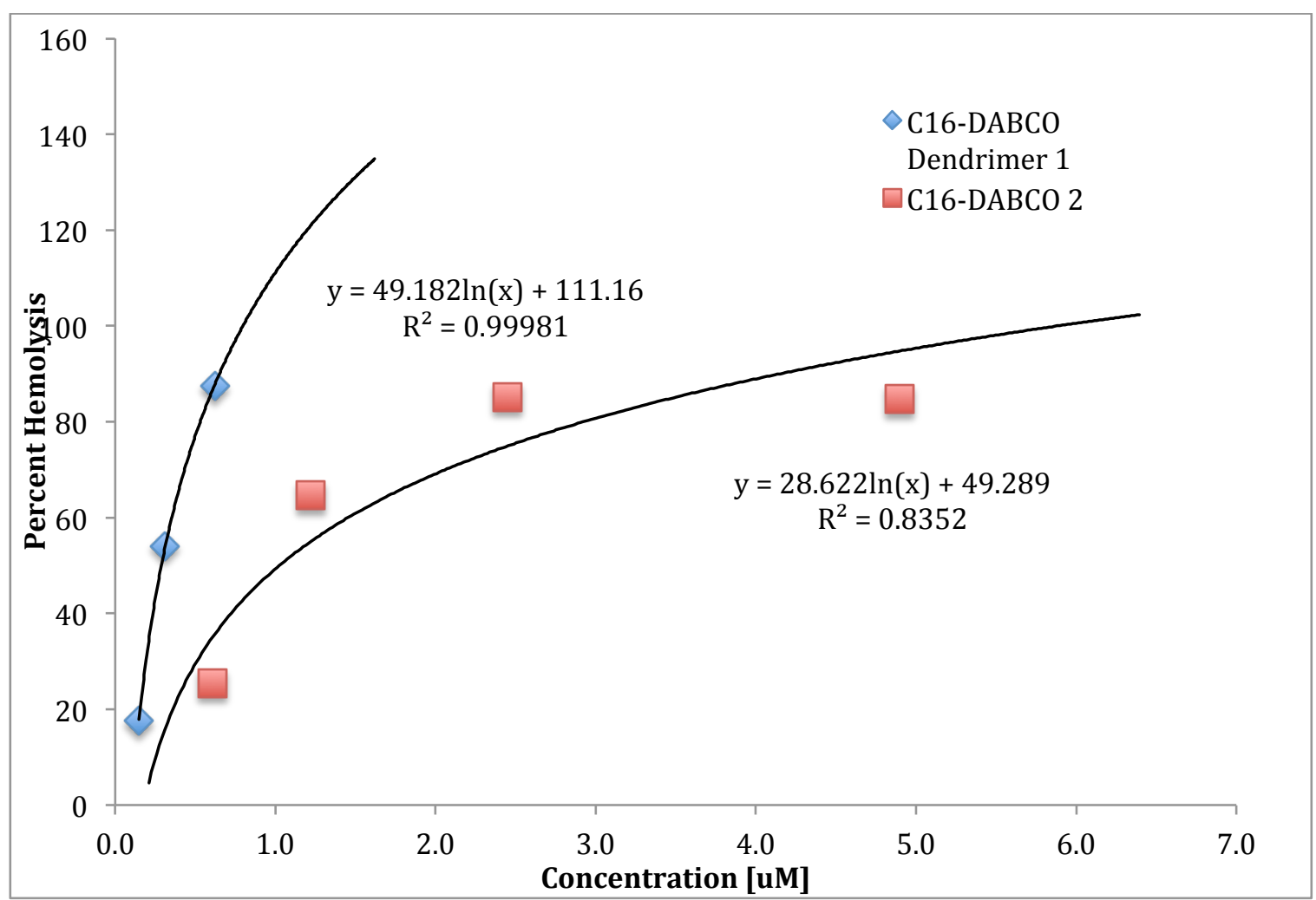

Figure S5. Red blood cell hemolysis for $\mathrm{C}_{16}$-DABCO dendrimer 1 and $\mathrm{C}_{16}$-DABCO monomer 2. 


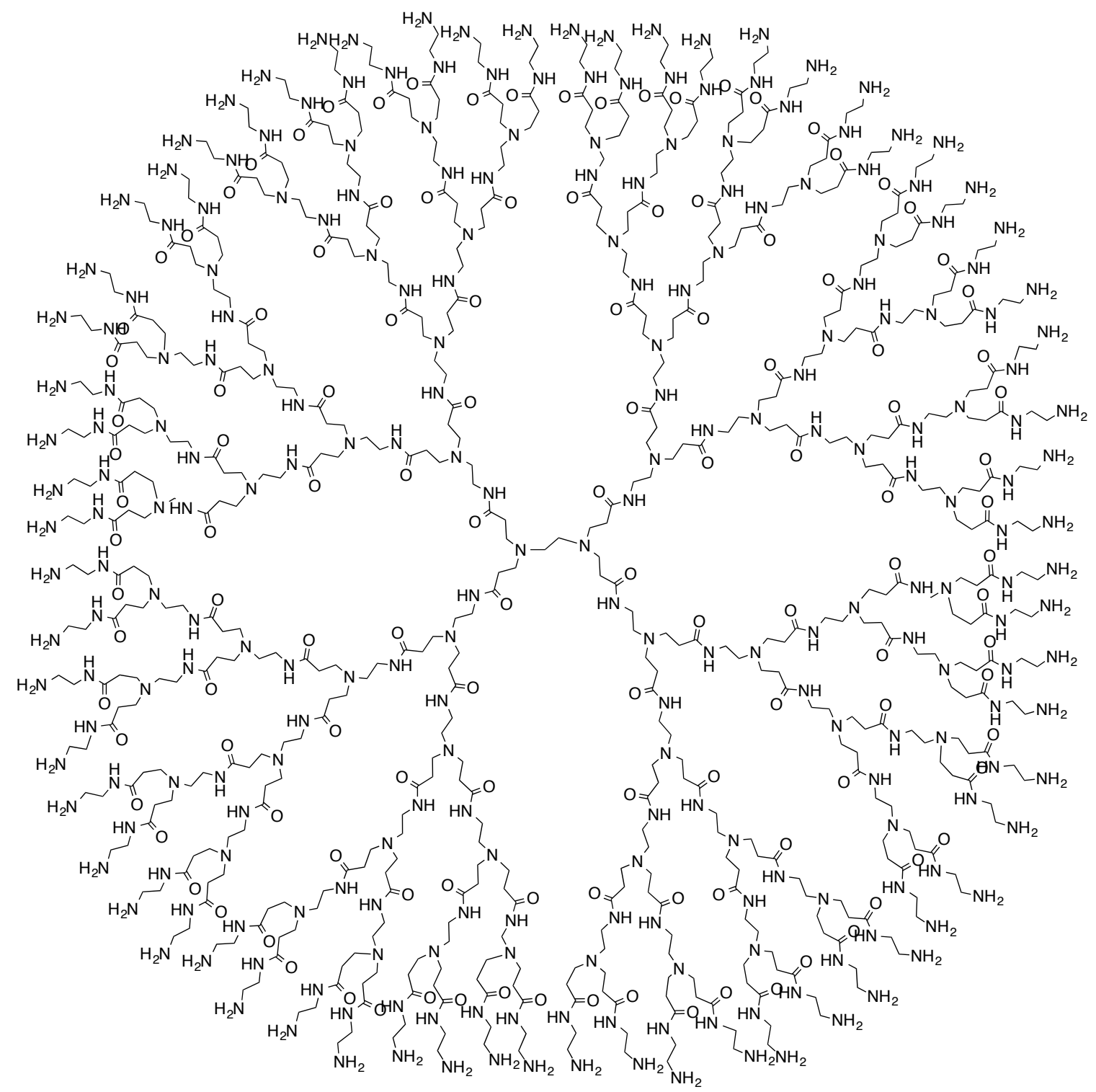

Figure S6. Fourth generation poly(amidoamine) dendrimer, i.e. G(4)-PAMAM. 
Table S1. Minimum Inhibitory Concentrations (MICs) for Dendrimer 1 and Monomer 2.

\begin{tabular}{lllllllll}
\hline $\begin{array}{l}\text { Microorganism } \\
\text { (Gram + or -) }\end{array}$ & $\begin{array}{l}\mathrm{C}_{16} \text {-DABCO } \\
\text { Dendrimer 1 } \\
\text { (per } \\
\mathrm{C}_{16} \text {-DABCO } \\
\text { group) }\end{array}$ & $\begin{array}{l}\mathrm{C}_{16} \text {-DABCO } \\
\text { Dendrimer 1 } \\
\text { (per } \\
\text { dendrimer) }\end{array}$ & $\begin{array}{l}\mathrm{C}_{16} \text {-DABCO } \\
\text { Monomer 2 }\end{array}$ & $\begin{array}{l}\mathrm{C}_{16} \text {-DABCO } \\
\text { Dendrimer 1 } \\
\text { (per } \\
\text { dendrimer) }\end{array}$ & $\begin{array}{l}\mathrm{C}_{16} \text {-DABCO } \\
\text { Monomer 2 }\end{array}$ & Ampicillin & Cephalexin & Streptomycin \\
\hline $\begin{array}{l}\text { Streptococcus } \\
\text { oralis }(+)\end{array}$ & $>165 \mu \mathrm{M}$ & $>20.0 \mathrm{uM}$ & $3033 \mu \mathrm{M}$ & $\begin{array}{l}>600 \\
(\mu \mathrm{g} / \mathrm{mL})\end{array}$ & $\begin{array}{l}1024 \\
(\mu \mathrm{g} / \mathrm{mL})\end{array}$ & $\mathrm{N} / \mathrm{A}$ & $\mathrm{N} / \mathrm{A}$ & $<34 \mu \mathrm{M}$ \\
$\begin{array}{l}\text { Staphylococcu } \\
\text { s aureus }(+)\end{array}$ & 1.1 & 0.133 & 11.8 & 4 & 4 & $<67 \mu \mathrm{M}$ & $<68 \mu \mathrm{M}$ & $<17$ \\
$\begin{array}{l}\text { Bacillus } \\
\text { cereus }(+)\end{array}$ & 1.1 & 0.133 & 17.7 & 4 & 6 & 27 & 41 & $\mathrm{~N} / \mathrm{A}$ \\
$\begin{array}{l}\text { Pseudomonas } \\
\text { aeruginosa }(-)\end{array}$ & 16 & 2.00 & 331.7 & 60 & 112 & $\mathrm{~N} / \mathrm{A}$ & $\mathrm{N} / \mathrm{A}$ & $<17$ \\
$\begin{array}{l}\text { Escherichia } \\
\text { coli }(-)\end{array}$ & 11 & 1.09 & 148.1 & 40 & 50 & 11 & 22 & $\mathrm{~N} / \mathrm{A}$ \\
\hline
\end{tabular}

Sample Calculation. Determining Concentration of Active Group.

From mass concentration of dendrimer to molar

$x \frac{\mathrm{mg}}{\mathrm{mL}} * \frac{1 \mathrm{~mol} \text { dendrimer }}{30,074 \mathrm{~g} \text { dendrimer }} * \frac{1 \mathrm{~g} \text { dendrimer }}{10^{3} \mathrm{mg} \text { dendrimer }} * \frac{1 \mathrm{~mL}}{10^{-3} \mathrm{~L}} * \frac{1 \mathrm{umol}}{10^{-6} \mathrm{~mol}}=y \frac{\text { umol }}{\mathrm{L}}=y u \mathrm{M}$

Equation 1. Solving for concentration of active group (per dendrimer basis)

(mass of a tosyl group) * (number of tosyl groups) + (mass of a C16DABCO group)

* (number of tosyl groups)

$=($ mass after tosyl and C16DABCO addition

- mass before tosyl and C16DABCO addition)

Equation 2. Determining ratio active group to non-active group vis NMR analysis ratio of tosyl methyl to C16DABCO methyl $(N M R)=\frac{\text { number of tosyl groups }}{\text { number of C16DABCO groups }}$

Two equations with two unknowns.

Solve for one variable in equation 2 in terms of the other variable; put answer in equation 1; solve for the only variable and put answer back into equation 1 to determine second variable. Variables are the number of tosyl and C16DABCO groups. 
Finally,

number of C16DABCO per dendrimer $*$ molarity of dendrimer $(y)$ $=$ molarity of $C 16 D A B C O$ per dendrimer

Figure S7. Biofilm Disruption Studies (log-kill platings) for S. aureus.

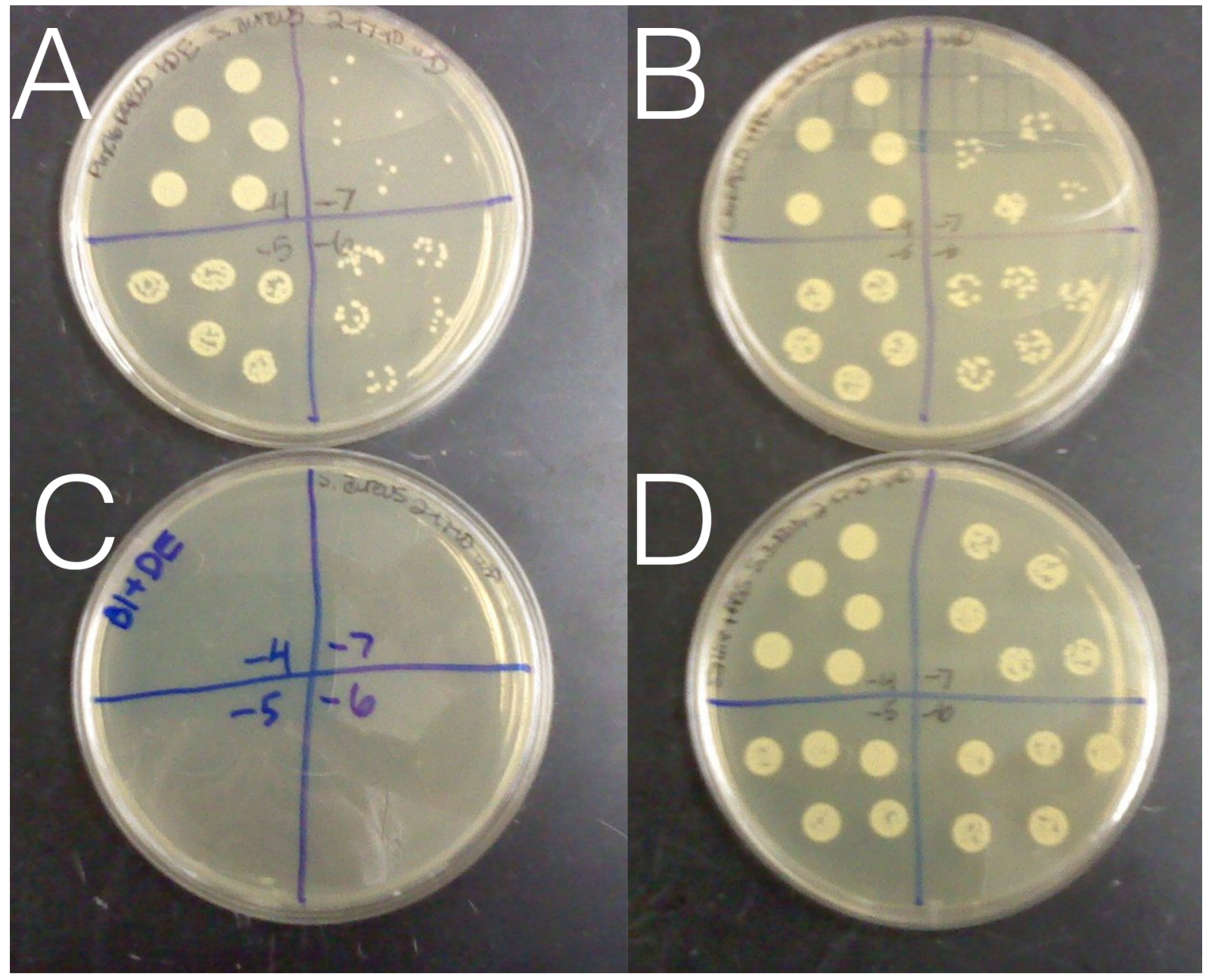

A) $\mathrm{C}_{16}$-DABCO dendrimer 1. B) $\mathrm{C}_{16}$-DABCO monomer 2. C) Bleach. D) Saline. 